\title{
The perceptions of nurses in a district health system in KwaZulu-Natal of their supervision, self-esteem and job satisfaction
}

\author{
LR Uys, D Soc Sc, School of Nursing, University of Natal \\ A Minnaar, PhD, School of Nursing, University of Natal \\ $S$ Reid, M Fam Med, Centre for Rural Health, University of Natal \\ JR Naidoo, B Nursing, School of Nursing, University of Natal
}

\section{Abstract \\ Background}

Supervision has been identified as a major issue in quality of care. Although increasing attention is being given to supervision in the District Health System, there have been no studies describing the current situation. This article describes a survey done in two health districts in KwaZulu-Natal involving 319 nurses from all types of government health care settings.

\section{Methods}

This was a quantitative descriptive study that described the current supervision, job satisfaction and self-esteem in two (2) health districts, that is the Ugu and the uThukela health districts. The three variables were described using a mailed questionnaire. A total 319 nurses participated in this study.

\section{Results}

The majority of the nurses $(53 \%)$ felt that positive supervision behaviours listed in a rating scale, occurred never or seldom. The average self-esteem score was very positive $(83 \%)$, and the average job satisfaction score was $60 \%$. Nurses were most satisfied with the factor reflecting "personal satisfaction about their contribution to the work" (72\%) and the least satisfaction with the factor that has to do with "pay and prospects" $(50 \%)$. While there was no relationship between any of the demographic variables and supervision, there was a low but significant relationship between supervision and job-satisfaction. A significant relationship was also found between the personal satisfaction factor of job satisfaction and self-esteem.

\section{Conclusion}

As nurses form the backbone of the health services, it is incumbent that health service managers safeguard the nursing workforce. Targeted strategies are necessary to ensure retention of the nurses for the health care of the South African population.

\section{Title}

A survey of the perceptions of nurses in a district health system in South Africa of their supervision, self-esteem and job-satisfaction.

\section{Background}

Supervision has been identified as a major issue in quality of care. It has been identified as a priority by the Initiative for Sub-district Support (ISDS) (1998), the Centre for Health and Social Studies (CHESS) (Gwele and Makahnya, 2001), and the Eastern Cape Department of Health (2000). Although increasing attention is being given to supervision in the District Health System, there has been no studies describing the current situation. Before this is done, that is outcome studies, it is impossible to get a clear picture of the problem, and plan interventions.

There seems to be two basic approaches to supervision, namely management supervision and consultative supervision. In management supervision, line managers supervise practice of the supervisee and have authority over them. Van Ooijen (2000, p. 26) points out that this type of supervision may be less effective in nursing, where it is seen as policing rather than supporting. Consultative supervision is done by a person who has no managerial responsibility for the supervisee, with the sole objective of 
support development. This is less common in nursing, but is the model used in the professions of social work and counseling.

In a concept analysis of "clinical supervision", Lyth $(2000$, p.728) defined it as "a support mechanism for practicing professionals within which they can share clinical organizational, developmental and emotional experiences with another professional in a secure, confidential environment in order to enhance knowledge and skills. This process will lead to an increasing awareness of other concepts including accountability and reflective practice." This is a more consultant-friendly definition than the one by Butterworth (1992, p.12) "an exchange between practicing professionals to enable the development of professional skills". These definitions lead one to expect distinct benefits for the service as well as for the practitioner.

A descriptive study was therefore undertaken to describe and explore the current practice with regard to supervision in different service settings (primary health care clinics, district hospitals, and regional hospitals) in a District Health Service (DHS) as seen by nurses in those settings. In a study by Seccombe and Smith (1997) in the UK, the supervisory relationships was central to job satisfaction. To explore the impact of supervision on the nurse, it was decided to also explore the job satisfaction and self-esteem of nurses in these settings, and its relationship with supervision.

\section{Literature review Supervision}

A number of articles describing research projects around supervision were found. Sloan (1999) described a qualitative study in which the experience of supervision of registered nurses working in a mental health setting was described. Individual questionnaires and one focus group interview was used. He found that although supervision was generally helpful, supervisees had trouble with not being able to choose a supervisor, and by the supervisor also being the manager, and keeping written records of interactions. Clinical supervision time was spent on clinical business, emotional support and professional development, with the process strongly resembling Proctor's three function model. This model was also used in a study by Bowles and Young (1999), in which a positive correlation was found between experience of supervisors and reported benefits, with benefits spread almost equally between the three functions (formative, restorative and normative).

White, Butterworth, Bishop, Carson, Jeacock and Clements (1998) also described clinical supervision from the perspective of supervisors interviewed individually. They did supervision individually or in groups, and saw supervisees fort-nightly or monthly. They dealt with practice, organization, management, education, training and personal development. They were convinced that supervision improved practice and strengthened relationships with work colleagues. However, they were concerned about the lack of time for supervision, and the lack of training for this aspect of their jobs.

Closer to home Kim, Tavrow, Malianga, Simba, Phiri and Gumbo (2000) explored the supervision process in Zimbabwe. They surveyed the supervision practice of sixteen (16) supervisors in eleven (11) districts by non-participant observation, using an observation schedule, as well as interviews and record reviews. Establishing rapport and giving feedback were the strengths of the supervisors. Weaknesses included not promoting participation, not discussing service standards, not assisting with problem-solving, and did not take a longer or more comprehensive view of problems. There was a lack of continuity between visits, and checklists used showed a range of limitations. A study by Troskie (1994), which surveyed the expressed needs of registered nurses for additional management training, supervision scored the lowest, together with orientation of staff. Registered nurses therefore did not feel that they needed additional training in this aspect.

\section{Job satisfaction}

Job satisfaction is a pleasurable or positive emotional state resulting from the appraisal of one's job experiences. Job satisfaction results from the perception that one's job fulfils or allows the fulfillment of one's own important job values (Locke, in Tovey and Adams, 1999, p. 152). This was measured using the Measure of Job Satisfaction (MJS), an instrument developed by Traynor and Wade (1993).

Job satisfaction is a heavily researched topic, not only in nursing (Tovey and Adams, 1999; Price, 2002), but also in medicine (Beasley, Kern, Howard and Kolodner, 1999). It has been pointed out that initially job satisfaction studies focused on the influence of job satisfaction on productivity, while later studies has recognized it as a quality of life issue pertaining to the welfare of workers (Westaway, Wessie, Viljoen, Booysen and Wolmarans, 1996). Job satisfaction has been successfully linked with strike action, absenteeism and turnover (Westaway et al, 1999).

Conceptually, job satisfaction is also discussed in the motivation theories such as Maslow and Hertzberg, since these theories address the antecedents to job satisfaction (Tovey and Adams, 1999). This was the approach followed by Fertig (1998) in a study of staff motivation done in the Uthukela District. He found salary, opportunities to learn, achievements, recognition by the community and taking part in decision-making to be most motivating to the respondents.

From the literature it is clear that job satisfaction is influenced by multiple factors (Kaplan, Boshoff and Kellerman, 1991). The categories used in different instruments developed to measure this concept, therefore also differs widely. Beasley et al (1999) found six facets (work with supervisees, colleague relations, resources, patient care, pay and promotion). Tovey and Adams (1999) researched the components to establish an empirical framework for such research. They identified the following topics from their data: job content, resource issues, professional concerns, profes- 
sional working relationships, emotional reactions to nursing and external pressures.

\section{Self- esteem}

Self - esteem is the belief about ones own worth, which allows for confident handling of Table two: Sample of two districts

\begin{tabular}{|l|l|l|l|l|l|l|}
\hline Setting & $\begin{array}{l}\text { Nursing } \\
\text { auxilliary }\end{array}$ & $\begin{array}{l}\text { Enrolled } \\
\text { nurse }\end{array}$ & $\begin{array}{l}\text { Registered } \\
\text { nurse }\end{array}$ & $\begin{array}{l}\text { Head } \\
\text { nurse }\end{array}$ & $\begin{array}{l}\text { Zone } \\
\text { matron }\end{array}$ & Total \\
\hline Missing data & 6 & 7 & 4 & 0 & 0 & $28(11)^{*}$ \\
\hline Mobile clinic & 1 & 0 & 0 & 0 & 0 & 1 \\
\hline Fixed clinic & 2 & 6 & 21 & 7 & 0 & 36 \\
\hline PHC centre & 5 & 9 & 4 & 0 & 0 & 18 \\
\hline District hospital & 22 & 26 & 33 & 11 & 2 & 94 \\
\hline Regional hospital & 34 & 33 & 62 & 10 & 2 & 141 \\
\hline TOTAL & 70 & 81 & 124 & 28 & 4 & 318 \\
\hline
\end{tabular}

* 11 respondents did not indicate their position.

life's problems,

as measured by Rosenberg's Self-esteem Scale. Westaway et al (1996), pointed out that initially job satisfaction studies focused on the influence of job satisfaction on productivity, while later studies recognized it as a quality of life issue pertaining to the welfare of workers and these authors have also found a positive relationship between selfesteem and job satisfaction.

\section{Research Methodology Research Design}

This was a descriptive study to describe the current supervision in two (2) health districts, as well as the job satisfaction and self-esteem of nurses in these two districts. All three variables, that is, supervision, job satisfaction and self-esteem were described using a mailed questionnaire.

\section{Setting}

The two districts involved are Ugu and Uthukela. These two districts were chosen because two different interventions around supervision were planned for these districts, and doing a baseline survey would allow for evaluation of the interventions. Both districts are seen as relatively typical rural districts in terms of their population and service spread. The two districts are briefly described in Table 1.

\section{Table one: Description of Ugu and Uthukela health districts in KwaZulu-Natal}

\begin{tabular}{|l|c|l|}
\hline Indicator & Ugu & Uthukela \\
\hline Regional Hospital & 1 & 1 \\
\hline District Hospital & 5 & 2 \\
\hline Community Health Centre (24hour) & 0 & 3 \\
\hline Fixed PHC Clinics (Provincial) & 34 & 25 \\
\hline Fixed PHC Clinics (Local Authority) & 14 & 9 \\
\hline Mobile Clinics & 7 & 18 \\
\hline
\end{tabular}

\section{Sample}

There are 1668 nurses in Ugu Health District, and 1250 in Uthukela Health District. In the Uthukela health district, the three (3) hospitals were selected, and in the Ugu health district, three (3) hospitals and in both districts six (6) clinics were randomly selected. All the nurses on duty on the day of a visit from the field worker were given a questionnaire to complete. A total of 248 nurses from Ugu district and only 71 from Uthukela district responded (319). Phone calls to the services in the Uthukela district lead to only a few more questionnaires being returned. This represents a $15 \%$ return in Ugu, and a $6 \%$ return in Uthukela.

Table 2 sets out the work settings of the sample. In the population in this district $17 \%$ of nurses work in PHC settings, $60 \%$ in district hospitals, and $23 \%$ in regional hospitals. In the sample the percentages were $17 \%, 29 \%$ and $44 \%$ respectively. Regional hospitals were therefore over represented in the sample at the expense of district hospitals. In terms of category of nurses, nursing auxiliaries make up $22 \%$ of the population in the district, enrolled nurses $25 \%$, registered nurses $41 \%$ and supervisors $2 \%$. In the sample 22\% were nursing Auxiliaries, 25\% Enrolled Nurses, 39\% Registered Nurses and $10 \%$ supervisors. The sample therefore seems to reflect the categories in the district quite accurately.

Only twenty-three (23) of the respondents were men (7\%), and the average age was 38 years (SD 12), with the majority (34\%) falling between 31 and 40 years, and a large number also between 41 and 50 years (28\%). On average the respondents had years of nursing experience, with an even spread from 1-5 years upwards to 20 years and more.

\section{Data collection}

Questionnaires were delivered by hand to all sampled services in the two districts. A letter explaining the research and asking the respondent to participate accompanied the questionnaires. A stamped, self-addressed envelope was attached to send the reply to the researchers at the University. 
Table three: The perception of nurses about their supervision

\begin{tabular}{|c|c|c|c|c|c|c|}
\hline & No resp & Never & Sometimes & Cum \% & Often & Always \\
\hline 1. Develops rapport with me & 30 & 35 & 99 & $52 \%$ & 65 & 89 \\
\hline 2. Discuss previous feedback & 11 & 33 & 83 & $40 \%$ & 80 & 111 \\
\hline 3. Encourage me to talk & 14 & 50 & 88 & $48 \%$ & 50 & 116 \\
\hline 4. Help me identify problems & 9 & 40) & 106 & $49 \%$ & 58 & 105 \\
\hline 5. Help me to solve problems & 11 & 41 & 100 & $48 \%$ & 65 & 101 \\
\hline 6. Give me feedback about my own performance & 11 & 86 & 98 & $61 \%$ & 49 & 74 \\
\hline 7. Give me feedback about the clinic/unit & 14 & 49 & 95 & $50 \%$ & 69 & 91 \\
\hline 8. Give information or on-the-job training & 16 & 50 & 104 & $54 \%$ & 79 & 69 \\
\hline 9. Discuss next visit or supervision session & 27 & 90 & 87 & $64 \%$ & 51 & 63 \\
\hline 10. Discuss the meaning of information & 18 & 76 & 93 & $59 \%$ & 61 & 70 \\
\hline 11. Makes suggestions & 14 & 36 & 95 & $46 \%$ & 63 & 110 \\
\hline \multirow[t]{2}{*}{$\begin{array}{l}\text { 12. Encourage client/patients to participate in } \\
\text { discussion }\end{array}$} & 14 & 77 & 94 & $59 \%$ & 61 & 72 \\
\hline & No resp & $\begin{array}{l}\text { Very } \\
\text { dissat } \\
\end{array}$ & Dissat & Cum \% & Satisf & Very satisf \\
\hline $\begin{array}{l}\text { In general, how satisfied are you with the } \\
\text { supervision you receive }\end{array}$ & 98 & 44 & 87 & $72 \%$ & 57 & 33 \\
\hline
\end{tabular}

The following data collection instruments were used:

Description of current supervision: A questionnaire was developed based on the observation schedule used in the Zimbabwe study (Kim et al, 2000). Twelve items described the supervision activities and respondents were asked to rate these for frequency, and one general item requested respondents to rate their satisfaction with supervision. This instrument was developed without reference to the different models of supervision, in an effort not to have an instrument biased towards a specific model of supervision. Self-esteem: The Rosenberg Self-Esteem Scale (RSE) was used to measure self-esteem. This is a 10 item 4-point scale with a coefficient alpha of 0,78 in both American and South African studies (in Westaway et al, 1996).

Job satisfaction: The Measure of Job Satisfaction (MJS) was developed and tested in the UK. It has shown an internal consistency of 0,88 on Cronbach alpha, and an interrater reliability of 0,86 on average. It showed a 0,83 correlation with another measure of job satisfaction (criterion validity) and was able to discriminate between different groups of nurses (Traynor and Wade, 1993). It has 38 Likert scale items (very satisfied to very dissatisfied) on a five-point scale.

Ethical clearance for the research was obtained from the University, the Provincial Department of Health and the Directors of the two health districts. The voluntary completion and mailing of the questionnaires by respondents were accepted as voluntary participation.

\section{Analyses}

Internal consistency of all the instruments was calculated using the Cronbach Alpha Correlation Coefficient. Frequen- cies, means, standard deviations were then calculated. The significance of differences between the two health districts was calculated using the Pearson Chi-Square test.

\section{Results}

\section{The current practice with regard to supervision}

Since this is the first time this scale was used, a Cronbach Alpha Correlation Coefficient was calculated, and was found to be 0,8996 . The inter-item variance was 0,05 , the standard deviation 10,7 and the mean 31 out of a total possible score of 48. A factor analysis was done, and this showed that items 1 and 12 had the lowest correlation with the rest of the items (both 0.4). It also showed only one factor with significant loadings from all items, except 13.

The responses of the 318 nurses in the sample are summarized in table three. On average, $53 \%$ of nurses rate the positive behaviours listed in the scale as occurring never or sometimes (see column 5). The percentage is in the $60 \%$ for two items (Give me feedback about my own performance, Discuss next visit or supervision session). On the item asking about their general satisfaction with supervision, $72 \%$ indicate dissatisfaction.

Nurses were also asked to identify their supervisor(s). On average the nurses identified 5 (4.8) people as their supervisors, and in many cases nurses from the same setting would name different supervisors.

Using the Spearman Rank Correlation no significant correlation was found between any of the demographic factors, 


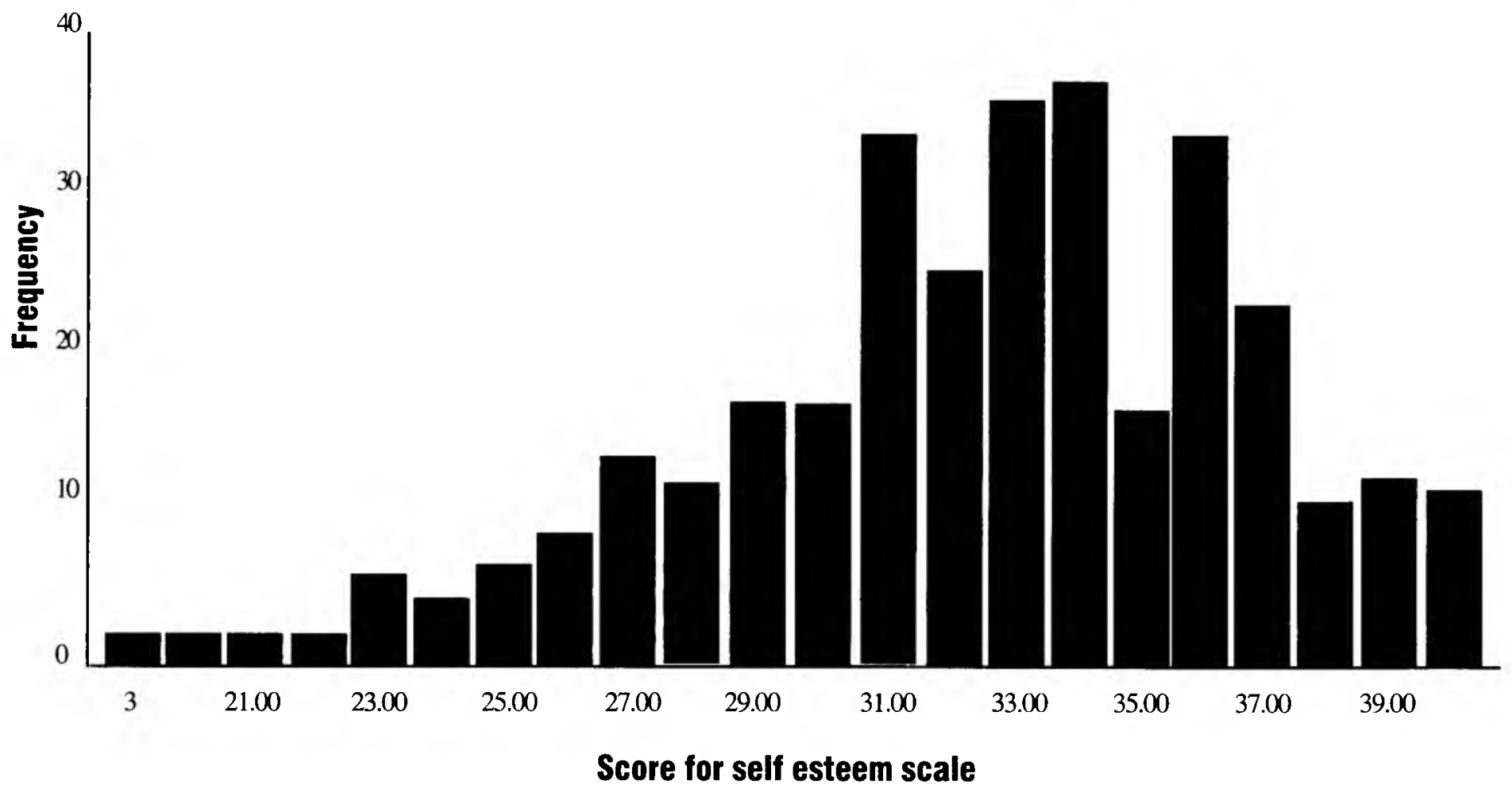

e.g. the age of the nurses, work setting or health district in which they worked.

\section{Self-esteem of nurses}

The internal consistency of this scale was tested using a Cronbach Alpha Coefficient, and was found to be 0,65. The average Self-esteem Score of the nurses was 33 out of a possible total of 40 , and a SD of 4,35 . Only three scored below 20 , as illustrated in figure 1 . To explore whether supervision influence self-esteem, a Chi-Square test was performed and no association was found $(r=0.287, \mathrm{df}=2$, $\mathrm{p}=0.866$ )

\section{Job-satisfaction of nurses}

The average job satisfaction score of the nurses was 113.56 out of a possible total score of $190(60 \%)$, with a higher score indicating greater satisfaction with supervision. The average score can also be stated as 2,6 with a SD of 0.7 , as was done by Traynor and Wade (1993). This score falls between dissatisfied (2) and neutral (3) (or 76 and 114), but is very close to a neutral score. The SD is 26.6 , which is within one category, and still does not move the majority of nurses to the "very dissatisfied" or the "satisfied" categories. A toral of $41 \%$ of the respondents falls in the two lowest categories (very dissatisfied and dissatisfied).

The scale consists of five (5) factors, and in Table 4 the dissatisfaction rating of respondents on each factor is summarized. There are three (3) factors on which the dissatisfaction scores are high. These are factor 5 - Satisfaction with Training (52\%), factor 4 - Satisfaction with pay and prospects (50\%), and factor 2-Satisfaction with workload
(41\%). On factor one, personal satisfaction, only $13 \%$ are dissatisfied, and $25 \%$ are very satisfied. The average scores on the factors were as follows: factor $1=3.7$, factor $2=2.8$, factor $3=3.4$, factor $4=2.3$ and factor $5=2.4$.

To find out whether supervision influences job satisfaction, a Chi Square correlation was calculated between these two sets of data. A low but significant relationship was found $(r=39.852$, d.f. $=9, p<0.000)$, and the Phi value for symmetric measures showed that this was a positive relationship. The relationship between self-esteem and job satisfaction was also explored by doing a Chi-square test, and no relationship was found $(r=4.225, \mathrm{df}=6, \mathrm{p}=0.646)$.

\section{Discussion}

It would seem that there is a general feeling of dissatisfaction amongst nurses with the supervision they receive ( $72 \%)$. More than half $(52 \%)$ of respondents saw positive supervision behaviours as happening never or only sometimes. In view of the poor correlation of the items on rapport and involving clients, these two items should perhaps be deleted from the scale. It is interesting that the factor on the Measure of Job Satisfaction (MJS) which deals with feeling supported (factor 3 ) did not show such a negative picture, with only $20 \%$ indicating dissatisfaction. When one looks at the individual items in this factor, however, it would seem that it is support coming from peers that is rated high in items such as "contact with colleagues" or "value placed on my work by colleagues".

The results contrast with the Zimbabwe study, where the rapport and feedback were strengths, and the solving of problems a weakness. Planning ahead for other supervi- 
Table four: Job satisfaction percentages of respondents of different factors

\begin{tabular}{|l|l|l|l|}
\hline Factors & $\begin{array}{l}\text { Dissatisfied } \\
\text { or very dissatisfied }\end{array}$ & Neutral & $\begin{array}{l}\text { Satisfied } \\
\text { or very satisfied }\end{array}$ \\
\hline 1. Personal satisfaction & 13 & 11 & 72 \\
\hline 2. Satisfaction with workload & 41 & 15 & 38 \\
\hline 3. Satisfaction with professional support & 20 & 13 & 63 \\
\hline 4. Satisfaction with pay and prospects & 50 & 17 & 26 \\
\hline 5. Satisfaction with training & 52 & 16 & $27^{*}$ \\
\hline
\end{tabular}

* Total \% does not come to $100 \%$ due to missing data

Table five: Comparison between job satisfaction scores of SA and UK nurses

\begin{tabular}{|l|l|l|}
\hline & SA & UK \\
\hline 1 Personal satisfaction & 3.7 & 3.8 \\
\hline 2 Satisfaction with workload & 2.8 & 2.9 \\
\hline 3. Satisfaction with professional support & 3.4 & 3.4 \\
\hline 4. Satisfaction with training & 2.3 & 3 \\
\hline 5. Satisfaction with Pay and Prospects & 2.4 & 3.3 \\
\hline
\end{tabular}

sion sessions was a weakness in both groups.

The relatively solid self-esteem of nurses is gratifying. This finding and the high level of personal satisfaction is somewhat surprising in the light of the their perceptions about poor supervision, high workload, and dissatisfaction with training, pay and prospects (factors $2,4 \& 5$ ). This might indicate that the South African nurse is challenged and sustained by the responsible role she plays as frontline worker in the country's health system.

The average self-esteem of this group of nurses (33) is a little lower compared to the average of a random national sample used by Westaway et al in 1996, which was 34,5. Although there is no significant relationship between selfesteem and job satisfaction, there is a positive relationship between the high scores on factor I of the MJS (Personal satisfaction) and high scores on the self-esteem measure. The high levels of personal satisfaction and the high selfesteem might serve to disguise the dissatisfaction in many other areas.

It is difficult to compare the average job satisfaction of this group of nurses with other South African samples, since the three (3) available studies (current, Kaplan et al, 1991, and Westaway et al, 1996) used different measuring instruments. However, Westaway et al (1996) found nurses to be the least satisfied with promotion and pay, and the most satisfied with supervision and co-workers. This is a similar finding to this study. Respondents in this study are nega- tive about three out of the four factors, which all has to do with negotiable job benefits.

When comparing the average scores of the different factors with the scores on these factors obtained by district nurses in the UK (Traynor and Wade, 1993), scores for factors 1 to 3 were remarkably similar (see table 5). However, when it came to the last two factors, the SA nurses scored much lower. Traynor and Wade compared six different groups of nurses with each other, and none of these groups scored as low as the SA nurses on the last two factors. This leads one to take the dissatisfaction in these areas more seriously, since it does not seem to be common to all nurses. In 1991 Kaplan et al's study compared the score of nurses in South Africa with that of other health professions, and found that it was not only the lowest, but that it was significantly lower than the other professions. It would therefore seem that these aspects need some attention. Whilst district management cannot address pay, which is negotiated nationally, they can address career development and training.

\section{Conclusion}

Nurses form the backbone of the health services in South Africa, especially in rural areas, where doctors and all other health professionals are a scarce resource. Attracting nurses to rural government services and keeping them there in the face of international recruitment is also becoming increasingly difficult. It is therefore incumbent on health service managers to safeguard the nursing workforce. This study points to particular problems that need to be addressed; the quality of supervision, the training opportunities and pay and prospects. Although it is safe to say that no group is ever satisfied with its pay, the comparison with other professions and with nurses internationally shows that this problem is real for South African nurses. Targeted strategies are necessary to ensure the retention of nurses for the health care of the South African population.

\section{References}

BEASLEY, B W; KERN, D E; HOWARD, D M \& KOLODNER, K 1999: A job-satisfaction measure of internal medicine residency program directors. Academic Medicine. 74(3): 263-270.

BOWLES, N AND YOUNG, C 1999: An evaluative study of clinical supervision based on Proctor's three function interactive model. Journal of Advanced Nursing. 30(4): 958 964. 
EASTERN CAPE DEPARTMENT OF HEALTH 2000: Clinic supervisors manual. Bisho: Department of Health

FERTIG, A 1998: Staff motivation in health facilities in the Uthukela Region, KZN, SA. Unpublished research report pp. 220-235.

GWELE, NS AND MAKHANYA.NJ 2001: The programme of support and training for Primary health Care co-ordinators in Region B - KZN and evaluation study. Durban: Health Systems Trust.

INITIATIVE FOR SUB-DISTRICT SUPPORT 1998: Supporting staff through effective supervision: How to assess, plan and implement more effective clinic supervision. KwikSwiz 15. Durban: Health Systems Trust.

KAPLAN, RA: BOSHOFF, A B \& KELLERMAN,AM 1991: Job involvement and job satisfaction of South African Nurses compared with other professions. Curationis. 14(1): 3-7.

KIM, YM P; TAVROW, L; MALIANGA, L; SIMBA, S; PHIRI, A \& GUMBO, P 2000: The quality of supervisorprovider interactions in Zimbabwe. Operations Research Results. 1(5): 1-16.

LYTH, GM 2000: Clinical supervision: a concept analysis. Journal of Advanced Nursing. 31(3): 722-729.

PRICE, M 2002: Job satisfaction of registered nurses working in an acute hospital. British Journal of Nursing. 11(4): 275-280.

SECCOMBE, I \& SMITH, G 1997: Taking part: Registered nurses and the labour market in 1997. Institute for Employment studies, London.

SLOAN, G 1999: Good characteristics of a clinical supervisor: a community mental health nurse perspective. Journal of Advanced Nursing. 30(3): 713-722.

TOVEY, EJ \& ADAMS, A E 1999: The changing nature of nurses' job satisfaction: an exploration of sources of satisfaction in the 1990s. Journal of Advanced Nursing. 30(1): 150-158.

TRAYNOR, M \& WADE, B 1993: The development of a measure of job satisfaction for use in monitoring the morale of community nurses in four trusts. Journal of Advanced Nursing. 18: 127-136.

TROSKIE, $R$ 1994: The need for management training by nurses registered for nursing administration. Curationis. 17(1): 40-45.

VAN OOLJEN, E 2000: Clinical supervision. A practical guide. Edinburgh: Churchill Livingstone.

WESTAWAY, MS; WESSIE, GM; VILJOEN, E; BOOYSEN, U \& WOLMARANS, L 1996: Job satisfac- tion and self-esteem of South African nurses. Curationis. 19(3): 17-20.

WHITE, E; BUTTERWORTH, T; BISHOP, V; CARSON J; JEACOCK, J \& CLEMENTS, A 1998: Clinical supervision: insider reports of a private world. Journal of Advanced Nursing. 28(1) 185-192. 